\title{
KEANEKARAGAMAN JENIS TUMBUHAN PAKU-PAKUAN (PTERIDOPHYTA) DAN KONDISI TEMPAT TUMBUHNYA PADA HUTAN RAWA GAMBUT SEKUNDER DAN LAHAN GAMBUT TERBUKA
}

\author{
(Diversity of Ferns (Pteridophyta) and Growing Conditions in Secondary Peat Swamp Forests \\ and Open Peatland)
}

\author{
Furwoko kirno, Dwi Astiani, Hanna Artuti Ekamawanti \\ Fakultas Kehutanan Universitas Tanjungpura Pontianak. J1. Daya Nasional Pontianak 78124 \\ Email: Furwoko1995@gmail.com.
}

\begin{abstract}
The activities of the community around the peat swamp forest cause disruption of the ecosystem from the sustainability of the forest area's resources. Land clearing and peatland fires also affect the presence of ferns. The new environmental conditions due to changes in land cover cause ferns to be affected by these changes. Kuala Dua Village Kubu Raya Regency has secondary peat swamp forest and open peat land due to fires 3-4 years earlier so it is overgrown with a variety of new types of flora, one of which is a type of fern. The objective of the study is to describe species diversity of ferns and their site conditions in secondary peat swamp forests and open peatlands of Kuala Dua Village, Kubu Raya District. This research was conducted with survey method using multiple plot samples. The plots determination was done by purposive sampling which was taken place on the site where there were many species of ferns land. Three plots were on each land covered condition with a plot size of $5 \mathrm{~m} \times 5 \mathrm{~m}$ that divided into 25 of a $1 \mathrm{~m} \times 1 \mathrm{~m}$ sub plots. The results show that 5 species of ferns found in peat swamp forest and 4 species of ferns were found on open peatlands. The species that has the highest INP value in the forest was Asplenium belangeri and the species that has the INP value in open peatland was Nephrolefis falcata. Dominant Index, Spesies Diversity Index and Spesies Abudance Index were 0,12 and 0,18;0,30 and 0,36;0,51 and 0,52 on the forest and open peatland respectively. The Similarity Index value (IS) of ferns in secondary peat swamp forest and open peatland is 44\%. The study shows dissimility of species fern in peat swamp forests and open peatlands.
\end{abstract}

Keywords: Open peatland, Pteridophyta, secondary peat swamp forest

\section{PENDAHULUAN}

Indonesia merupakan salah satu negara yang memiliki keanekaragaman hayati tumbuhan tertinggi di dunia, salah satu jenis tumbuhan yang banyak hidup di hutan Indonesia adalah tumbuhan pakupakuan (Pteridophyta) (Sandy et al., 2016). Tumbuhan paku (Pteridophyta) tersebar hampir 10.000 spesies di seluruh dunia dan diperkirakan sekitar 4000 spesies tumbuhan paku yang tumbuh di Indonesia yang sebagian besar tumbuh di daerah tropika basah yang lembab (Kusmana dan Hikmat, 2015).

Tumbuhan paku-pakuan mempunyai peranan yang sangat penting dalam ekosistem hutan dan manusia. Tumbuhan paku-pakuan pada ekosistem hutan berperan dalam pembentukan humus dan melindungi tanah dari erosi. Tumbuhan paku-pakuan bagi kehidupan manusia berpotensi sebagai sayur-sayuran, tanaman hias, maupun sebagai obat-obatan tradisional (Efendi et al., 2013). 
Tumbuhan paku dapat tumbuh dan berkembang dengan baik di lahan terbuka. Tumbuhan paku merupakan tumbuhan perintis setelah terjadi kebakaran hutan ataupun di hutan yang tertutup tajuk pohon dengan intensitas cahaya matahari yang cukup dan derajat keasaman $(\mathrm{pH})$ berkisar antara 3,5-6,5 serta intensitas suhu yang berkisar antara $21-27^{\circ} \mathrm{C}$ untuk mendukung pertumbuhannya (Khamalia et al., 2018).

Aktivitas masyarakat sekitar hutan rawa gambut menyebabkan terganggunya ekosistem dari kelestarian sumberdaya kawasan hutan. Pembukaan lahan dan kebakaran lahan gambut berpengaruh juga pada keberadaan tumbuhan paku-pakuan. Kondisi lingkungan yang baru akibat perubahan tutupan lahan menyebabkan tumbuhan paku-pakuan terkena dampak dari perubahan tersebut. Desa Kuala Dua Kabupaten Kubu Raya mempunyai hutan rawa gambut sekunder dan lahan gambut terbuka akibat terjadinya kebakaran 3-4 tahun sebelumnya sehingga ditumbuhi oleh beragam jenis flora yang baru salah satunya jenis paku-pakuan. Keanekaragam jenis dan kondisi tempat tumbuh pakupakuan yang terdapat di lahan gambut bekas kebakaran ini belum teridentifikasi jenisnya, oleh sebab itu diperlukan penelitian tentang keanekaragaman jenis dan kondisi tempat tumbuh paku-pakuan dilahan tersebut. Penelitian ini dilakukan dengan tujuan mendeskripsikan keanekaragaman jenis tumbuhan pakupakuan dan kondisi tempat tumbuhnya pada hutan rawa gambut sekunder dan lahan gambut terbuka di Desa Kuala Dua Kabupaten Kubu Raya.

\section{METODE PENELITIAN}

Penelitian ini telah dilaksanakan pada hutan rawa gambut sekunder dan lahan gambut terbuka di Desa Kuala Dua kabupten Kubu Raya pada bulan Juni Juli 2018. Objek penelitian adalah semua jenis tumbuhan paku-pakuan yang ditemukan dan kondisi tempat tumbuhnya pada hutan rawa gambut sekunder dan lahan gambut terbuka. Metode yang digunakan pada penelitian ini adalah metode survei menggunakan petak ganda. Peletakan petak di lakukan dengan cara purposive sampling yaitu diletakkan pada lokasi yang ditemui banyak jenis pakupakuan. Ukuran petak yaitu $5 \mathrm{~m}$ x $5 \mathrm{~m}$ yang dibagi ke dalam 25 sub petak dengan ukuran $1 \mathrm{~m}$ x $1 \mathrm{~m}$ (Gambar 1). Jumlah petak yang dibuat pada penelitian ini yaitu 3 petak pada masing-masing kondisi tutupan lahan. 


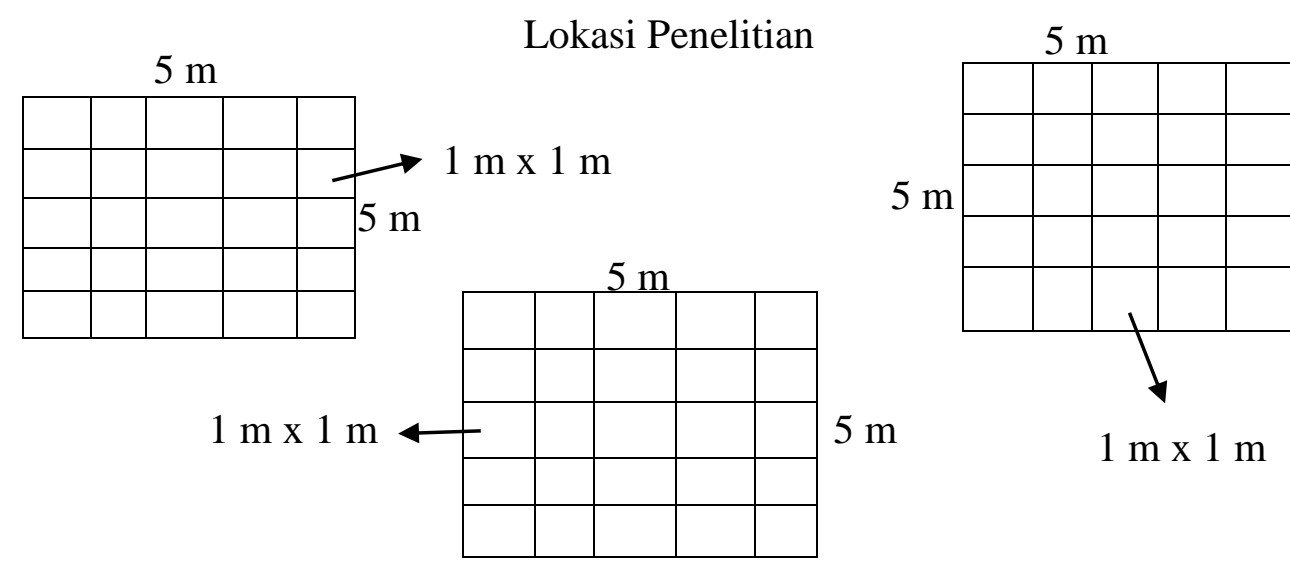

Gambar 1. Desain Petak Pengamatan pada Satu Tutupan Lahan (plot design observation on one land cover).

Analisis data yang digunakan dalam penelitian ini sebagai berikut:

1. Indeks nilai penting (Soerianegara dan Indryanto, 1998)

INP tumbuhan paku = kerapatan relatif $(\mathrm{KR})+$ frekuensi relatif $(\mathrm{FR})$

2. Indeks Dominansi (Simson Indeks)

Digunakan untuk menentukan dominansi suatu jenis didalam suatu komunitas atau penggolongan jenis (Odum, 1993).

$$
\mathrm{C}=\sum\left(\frac{\mathrm{Ni}}{\mathrm{N}}\right)^{2}
$$

Dimana:

C : Indeks dominasi.

$\mathrm{Ni}$ : Indeks nilai penting jenis ke-i.

$\mathrm{N}$ : Total indeks nilai penting.

3. Indeks keanekaragaman jenis (H')

Keanekaragaman jenis adalah suatu indeks keanekaragaman secara keseluruhan dalam suatu tipe hutan yang dapat ditentukan dengan rumus ShanonWeiner (Fachrul, 2012).

$\mathrm{H}^{\prime}=\mathrm{Pi}$ Ln Pi

$\mathrm{Pi}=\frac{\mathrm{ni}}{\mathrm{N}}$

\section{Dimana:}

$\mathrm{H}^{\prime}$ : Indeks keanekaragaman jenis.

ni : Jumlah individu dari suatu jenis.

$\mathrm{N}$ : Jumlah total individu dari seluruh jenis.

Ln : Logaritma natural.

4. Indeks kelimpahan jenis

Indeks kelimpahan jenis dipengaruhi oleh keanekaragaman jenis dan jumlah jenis yang digunakan rumus indeks Evennes (Odum, 1993).

$\mathrm{e}=\frac{\mathrm{H}^{2}}{\log \mathrm{S}}$

Dimana:

e $\quad$ : Indeks kelimpahan jenis.

H' : Indeks keanekaragaman jenis.

S : Jumlah dari seluruh jenis.

5. Indeks kekayaan jenis (d)

Indeks kekayaan jenis adalah rasio perbandingan jenis antara jumlah jenis secara keseluruhan terhadap jumlah jenis yang teramati terhadap suatu luasan tertentu (Odum, 1993). Adapun indeks kekayaan jenis dapat dihitung dengan rumus sebagai berikut:

$$
d=\frac{S-1}{\log N}
$$


6. Kesamaan komunitas.

Indeks similaritas soransen digunakan untuk membandingkan kesamaan antar stasiun berdasarkan parameter biologi atau kesamaan jenis antar spesies (Odum, 1993). Berikut rumusnya:

$$
\text { IS }=\frac{2 \mathrm{C}}{\mathrm{A}+\mathrm{B}}
$$

Dimana:

IS : Indeks Sorensen.

A : Jumlah jenis di hutan rawa gambut sekunder.

B : Jumlah jenis di lokasi lahan terbuka gambut.

C : Jumlah jenis yang sama pada dua unit contoh yang dibandingkan.

HASIL DAN PEMBAHASAN
Berdasarkan hasil penelitian yang telah dilakukan pada hutan rawa gambut sekunder dan lahan gambut terbuka di Desa Kuala Dua Kabupaten Kubu Raya Kalimantan Barat, ditemukan 5 jenis tumbuhan paku-pakuan pada hutan rawa gambut sekunder dan 4 jenis tumbuhan paku-pakuan pada lahan gambut terbuka. Jenis paku-pakuan yang terdapat pada dua lokasi tersebut digolongkan dalam dua kelompok menurut cara hidupnya atau tempat tumbuhnya yaitu terestrial dan epifit. Jenis-jenis tumbuhan paku-pakuan yang ditemukan dapat dilihat pada Tabel 1.

Tabel 1. Jenis Paku-pakuan yang Ditemukan dan Habitat Tumbuhnya (Species fern and growing habitats).

\begin{tabular}{|c|c|c|c|c|}
\hline No & Nama Lokal & Nama Latin & Family & Habitat \\
\hline & \multicolumn{4}{|c|}{ Rawa Gambut Sekunder } \\
\hline 1 & Paku Tamaga & $\begin{array}{l}\text { Asplenium belangeri } \\
\text { (Bory) Kze. }\end{array}$ & Aspleniaceae & Terestrial \\
\hline 2 & Paku Cenceran & $\begin{array}{l}\text { Nephrolefis falcata } \\
\text { (Cap.) C. Chr. }\end{array}$ & Driopteridaceae & Terestrial \\
\hline 3 & Paku Panjang & $\begin{array}{l}\text { Asplenium longissimum } \\
\text { Blume. }\end{array}$ & Aspleniaceae & Terestrial \\
\hline 4 & Paku Sarang Burung & Asplenium nidus L. & Aspleniaceae & Epifit \\
\hline \multirow[t]{2}{*}{5} & Paku Hijau & $\begin{array}{l}\text { Heterogonium } \\
\text { Giganteum (BI.) Holtt. }\end{array}$ & Tectariaceae & Terestrial \\
\hline & \multicolumn{4}{|c|}{ Lahan Gambut Terbuka } \\
\hline 1 & Paku Cenceran & $\begin{array}{l}\text { Nephrolefis Falcata } \\
\text { (Cap.) C. Chr. }\end{array}$ & Driopteridaceae & Terestrial \\
\hline 2 & Lemiding & $\begin{array}{l}\text { Stechlanaena palustris } \\
\text { (Burm) Bedd. }\end{array}$ & Blechnaceae & Terestrial \\
\hline 3 & Resam & $\begin{array}{l}\text { Gleichenia Linearis } \\
\text { (Burm.) Charke. }\end{array}$ & Gleicheniales & Terestrial \\
\hline 4 & Paku Sarang Burung & Asplenium Nidus L & Aspleniaceae & Epifit \\
\hline
\end{tabular}

Indeks Nilai Penting (INP) Komunitas

Paku-Pakuan Pada Hutan Rawa

Gambut Sekunder dan Lahan Gambut

Terbuka di Desa Kuala Dua Kalimantan Barat.
Analisis data dilakukan untuk mengetahui keanekaragaman jenis tumbuhan paku-pakuan pada hutan rawa gambut sekunder dan lahan gambut terbuka dengan parameter kerapatan jenis, indeks nilai penting (INP) (Tabel 2). 
Tabel 2. Analisis Kerapatan Jenis, Indeks Nilai Penting (INP) (Type density analisys and imfortant value index (INP)).

\begin{tabular}{llcc}
\hline No & \multicolumn{1}{c}{ Jenis } & Kerapatan/ha & INP \\
\hline & Rawa Gambut Sekunder & & \\
1 & Asplenium belangeri & 16266,67 & 28,87 \\
2 & Nephrolefis falcata & 11333,33 & 19,71 \\
3 & Asplenium longissimum & 2000 & 5,46 \\
4 & Asplenium nidus & 533,33 & 2,55 \\
5 & Heterogonium giganteum & 133,33 & 2,55 \\
\hline \multicolumn{2}{c}{ Jumlah } & 59,06 \\
\hline \multirow{2}{*}{ Lahan Gambut Terbuka } & 16400 & 38,87 \\
2 & Nephrolefis falcata & 4533,33 & 14,64 \\
3 & Stechlaena palustris & 3333,33 & 12,53 \\
4 & Aspleichenia linearis & 266,67 & 3,80 \\
\hline \multicolumn{2}{c}{ Jumlah } & 69,85 \\
\hline
\end{tabular}

Tumbuhan paku-pakuan pada hutan rawa gambut sekunder menguasai sekitar 29\% dibandingkan dengan jenisjenis tumbuhan bawah lainnya sedangkan pada lahan gambut terbuka sedikit lebih tinggi tingkat penguasaan tumbuhan paku-pakuan sekitar 34\% dari tumbuhan bawah lainnya. Nilai kerapatan tertinggi yang didapat dari banyaknya jumlah individu dalam areal seluas $0,0075 \mathrm{Ha}$ pada hutan rawa gambut sekunder adalah dari jenis $A$. belangeri dengan tingkat kerapatan 16266,67 individu/ha, sedangkan tingkat kerapatan terendah adalah jenis $H$. giganteum dengan tingkat kerapatan 133,33 individu/ha. Nilai kerapatan tertinggi pada lahan gambut terbuka adalah jenis $N$. falcata dengan nilai kerapatan 16400 individu/ha, sedangkan tingkat kerapatan yang terendah adalah dari jenis A. nidus dengan nilai 266,67 individu/ha. Kerapatan jenis pada dua lokasi tersebut memiliki perbedaan, hal ini dapat dipengaruhi oleh faktor tempat tumbuhnya.

Indeks Nilai Penting (INP) adalah parameter kuantitatif yang digunakan untuk menyatakan tingkat penguasaan spesies-spesies dalam suatu komunitas (Indrianto, 2006). Menurut Soerianegara dan Indrianto (1989), suatu jenis yang memiliki peran pada suatu komunitas dicirikan dengan nilai penting yang tertinggi karena merupakan jumlah dari kepadatan relatif (KR) dan frekuensi relatif (FR). Semakin tinggi indeks nilai penting suatu jenis maka semakin tinggi penguasaannya di dalam suatu komunitas tempat jenis tersebut tumbuh. 
Berdasarkan hasil analisis data yang dilakukan, tingkat penguasaan tertinggi pada hutan rawa gambut sekunder adalah jenis $A$. belangeri yaitu $28,9 \%$ dari sesama jenis paku-pakuan atau sekitar $14,5 \%$ dari seluruh tumbuhan bawah. Tingginya nilai INP pada jenis $A$. belangeri menunjukan bahwa jenis ini menjadi penentu pada komunitas (ekosistem) hutan rawa gambut sekunder. Hal ini dibuktikan dengan ditemukannya jenis paku ini pada hampir setiap petak pengamatan. Nilai INP tertinggi pada lahan gambut terbuka adalah jenis $N$. falcata yaitu 38,87\% dari sesama jenis paku-pakuan atau sekitar $19 \%$ dari seluruh tumbuhan bawah. tingginya nilai INP pada jenis $N$. falcata menunjukan bahwa jenis ini menjadi penentu pada komunitas (ekosistem) lahan gambut terbuka, hal ini dibuktikan juga dengan ditemukannya jenis paku ini pada setiap petak pengamatan.

Tingginya nilai INP dipengaruhi oleh faktor genetik yang baik dan juga sangat dipengaruhi oleh interaksinya terhadap lingkungan seperti kondisi tanah, iklim mikro, mikroorganisme dan juga kompetisi dengan organisme lain, dengan kata lain tumbuhan-tumbuhan yang mempunyai adaptasi yang tinggilah yang bisa hidup mendominasi di suatu daerah. Tingginya nilai INP juga dipengaruhi pula oleh pertumbuhan atau kemampuan berkembangbiak dari suatu jenis tanaman seperti tanaman paku (Betty et al., 2015).

Tabel 3. Rekapitulasi Indeks Dominansi (C), Indeks Keanekaragaman Jenis (H'), Indeks Kekayaan Jenis (e), dan Indeks Kelimpahan Jenis pada Hutan Rawa Gambut Sekunder dan Lahan Gambut Terbuka (Recapitulation of dominance index $(C)$, spesies diversity index, spesies richness index (e), and abudance index in secondary peat swamp forest open peat land).

\begin{tabular}{llcccc}
\hline No & \multicolumn{1}{c}{ Lokasi } & C & H' & e & d \\
\hline 1 & Hutan rawa gambut sekunder & 0,12 & 0,36 & 0,52 & 4,59 \\
2 & Lahan terbuka gambut & 0,18 & 0,30 & 0,51 & 3,57 \\
\hline
\end{tabular}

Indeks dominasi (C) digunakan untuk menentukan dominansi suatu jenis dalam suatu komunitas. Kriteria dalam menentukan dominansi menurut Indeks Simpson yaitu ID = 0 menunjukkan indeks dominansi rendah atau tidak ada suatu jenis yang mendominansi terhadap jenis lainnya, sedangkan ID = 1 menunjukkan dominansi tinggi atau terdapat spesies yang mendominansi jenis jenis yang lainnya.

Berdasarkan analisis data diketahui rata-rata indeks dominansi jenis paku- pakuan pada hutan rawa gambut sekunder dan lahan gambut terbuka berturut-turut 0,12 dan 0,18. Berdasarkan kriteria penentuan dominansi dapat dikatakan bahwa jenis paku-pakuan pada dua lokasi tersebut termasuk rendah. Hal ini menunjukkan tidak ada paku-pakuan yang terlalu mendominasi atau tidak terjadi pemusatan terhadap jenis tertentu pada hutan rawa gambut sekunder dan lahan gambut terbuka di Desa Kuala Dua Kabupaten Kubu Raya Kalimantan Barat. 
Indeks keanekaragaman jenis (H') digunakan untuk mengukur stabilitas komunitas, yaitu kemampuan suatu komunitas untuk menjaga dirinya tetap stabil meskipun ada gangguan terhadap komponennya. Suatu komunitas dikatakan memiliki keanekaragaman jenis yang tinggi jika komunitas tersebut tersusun banyak jenis. Suatu komunitas dikatakan memiliki keanekaragaman jenis rendah jika komunitas itu disusun oleh sedikit jenis (Tujudki et al. 2014)

Keanekaragaman jenis yang tinggi menunjukkan bahwa suatu komunitas memiliki kompleksitas yang tinggi atau tersusun oleh banyak jenis. Kriteria untuk menentukan tingkat keanekaragaman yaitu $\mathrm{H}^{\prime}<1$, menunjukkan keanekaragaman jenis yang rendah, $1<\mathrm{H}>3=$ menunjukkan tingkat keanekaragaman jenis yang sedang dan $\mathrm{H}^{\prime}>3=$ menunjukkan tingkat keanekaragaman jenis tinggi (Mason dalam Khamalia et al. 2018).

Berdasarkan hasil perhitungan indeks keanekaragaman jenis paku-pakuan pada hutan rawa gambut sekunder dan lahan gambut terbuka berturut-turut 0,30 dan 0,36 . Nilai keanekaragaman jenis tumbuhan paku-pakuan pada kedua lokasi tersebut tergolong rendah karena $\mathrm{H}^{\prime}<1$. Keanekaragaman jenis sangat dipengaruhi oleh kondisi tempat tumbuh. Kebakaran hutan yang pernah terjadi pada dua lokasi tersebut bisa saja mempengaruhi keanekaragaman jenis paku-pakuan tersebut.

Indeks kelimpahan jenis (e) dipengaruhi oleh indeks keanekaragaman jenis dan jumlah jenis yang ditemukan di dalam suatu area. Nilai indeks kelimpahan jenis berada diantara $0-1$, jika nilai kelimpahan semakin mendekati 1 maka kelimpahan semakin tinggi. Berdasarkan analisis data indeks kelimpahan jenis pada hutan rawa gambut sekunder dan lahan gambut terbuka berturut-turut 0,51dan 0,52. Hal ini menunjukkan bahwa kekayaan jenis paku-pakuan pada hutan rawa gambut sekunder dan lahan gambut terbuka di Desa Kuala Dua Kabupaten Kubu Raya Kalimantan Barat termasuk kategori sedang.

Indeks Kekayaan Jenis (d) merupakan jumlah individu suatu jenis yang ditemukan selama pengamatan. Indeks kekayaan jenis berbanding lurus dengan Indeks Keanekaragaman Jenis. Berdasarkan hasil analisis data untuk tumbuhan paku pada dua lokasi penelitian yang mempunyai tutupan lahan yang berbeda, dapat diketahui nilai Indeks Kekayaan Jenis adalah 3,57 dan 4,59. Karena berbanding lurus dengan nilai keanekaragaman maka kekayaan jenis paku-pakuan pada hutan rawa gambut sekunder dan lahan gambut terbuka di Desa Kuala Dua Kabupaten Kubu Raya Kalimantan Barat termasuk pada kategori rendah.

$\begin{array}{llr}\text { Nilai indeks } & \text { kesamaan } \\ \text { menggambarkan tingkat kesamaan } & \text { kan } \\ \text { komposisi spesies dan stuktur dari dua } \\ \text { komunitas atau sampling yang }\end{array}$ dibandingkan (Indrianto, 2006). Kriteria untuk menentukan Indeks Similaritas yaitu IS $<50 \%=$ menunjukkan suatu komunitas sama sekali berbeda, $50 \%<$ IS > 75\%, menunjukkan suatu komunitas mirip dan IS $>75 \%=$ menunjukkan suatu komunitas sama (Magurran, 1988). Nilai indeks 
similaritas tumbuhan paku-pakuan pada hutan rawa gambut sekunder dan lahan terbuka gambut di Desa Kuala Dua Kabupaten Kubu Raya Kalimantan Barat yaitu $44 \%$. Berdasarkan kriteria penentuan IS dapat dikatakan bahwa komunitas jenis paku-pakuan pada dua lokasi tersebut memiliki ketidaksamaan. Jenis $N$. falcata dan A. nidus ditemukan pada dua lokasi tersebut. Hal ini menunjukkan bahwa jenis paku-pakuan tersebut dapat hidup pada dua kondisi tempat tumbuh yang berbeda namun hanya pada tempat tumbuh tertentu saja dapat hidup dengan baik.

\section{Analisis Tempat Tumbuh}

Kondisi tempat tumbuh paku-pakuan seperti suhu tanah, kelembaban udara, intensitas cahaya dan $\mathrm{pH}$ tanah serta tinggi muka air pada hutan rawa gambut sekunder dan lahan gambut terbuka disajikan pada Tabel 4 .

Tabel 4. Rerata Hasil Pengukuran Kondisi Tempat Tumbuh dan Standar Eror Terhadap Kondisi Tempat Tumbuh pada Hutan Rawa Gambut Sekunder dan Lahan Gambut Terbuka di Desa Kuala Dua Kabupaten Kubu Raya Kalimantan Barat (The verage measurement results of growing place condition in secondary peat wamp forest and open peat land in Kuala Dua village Kubu Raya district West Kalimantan).

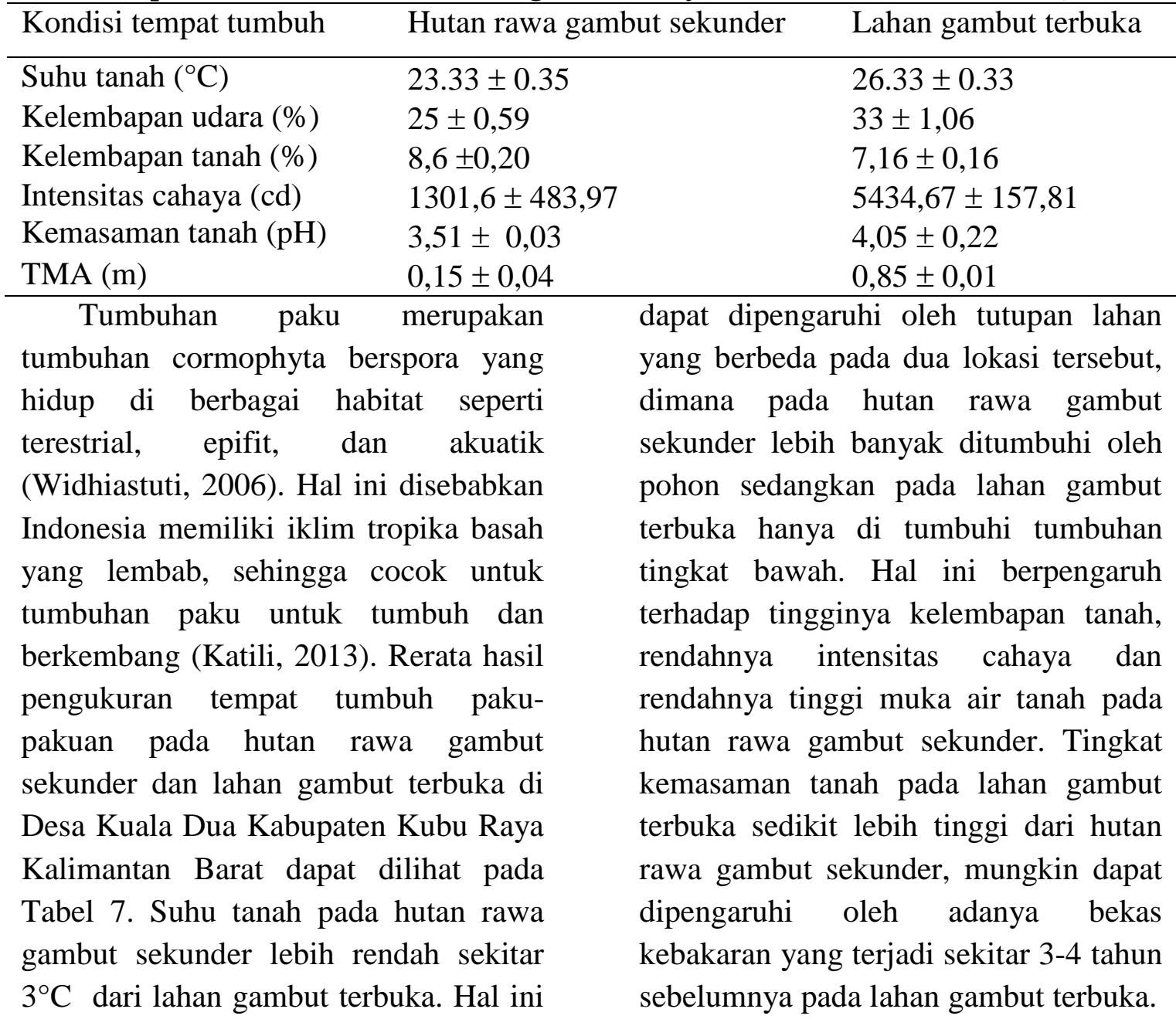




\section{KESIMPULAN}

Hasil penelitian keanekaragaman tumbuhan paku-pakuan pada hutan rawa gambut sekunder dan lahan gambut terbuka di Desa Kuala Dua Kabupaten Kubu Raya Kalimantan Barat menunjukkan:

1. Hutan rawa gambut sekunder ditemukan 5 jenis paku-pakuan, sedangkan pada lahan gambut terbuka ditemuka 4 jenis pakupakuan. Jenis paku-pakuan yang terdapat di kedua lokasi ini digolongkan ke dalam 2 kelompok menurut cara hidupnya atau tempat tumbuhnya secara terestrial dan epifit. Keanekaragaman jenis pakupakuan pada hutan rawa gambut sekunder dan lahan gambut terbuka relatif rendah dengan nilai 0,30 dan 0,36 . Indeks similaritas tumbuhan paku-pakuan pada hutan rawa gambut sekunder dan lahan gambut terbuka tidak memiliki kesamaan habitat tempat tumbuhnya.

2. Kondisi tempat tumbuh paku-pakuan menyatakan bahwa rerata suhu tanah harian pada hutan rawa gambut sekunder lebih rendah sekitar $3^{\circ} \mathrm{C}$ dari lahan gambut terbuka. Hal ini dipengaruhi oleh adanya perbedaan vegetasi yang tumbuh pada dua lokasi tersebut, sehingga berpengaruh juga terhadap kelembapan tanah, intensitas cahaya dan tinggi muka air tanah, tetapi tingkat kemasaman tanah $(\mathrm{pH})$ pada lahan gambut terbuka sedikit lebih tinggi dari hutan rawa gambut sekunder, mungkin dapat dipengaruhi oleh adanya bekas kebakaran yang terjadi sekitar 3-4 tahun sebelumnya pada lahan gambut terbuka.

\section{SARAN}

Tumbuhan paku memiliki potensi pemanfaatan yang cukup baik untuk dikembangkan lebih lanjut sebagai bahan obat, bahan makanan dan dan $\underline{\text { tanaman hias sehingga perlu dilakukan }}$ penelitian tentang pemanfaatan tumbuhan paku pada hutan rawa gambut sekunder dan lahan gambut terbuka di Desa Kuala Dua Kabupaten Kubu Raya.

\section{UCAPAN TERIMA KASIH}

Penulis ucapkan banyak terima kasih kepada Dwi Astiani dan Hanna Artuti Ekamawanti atas saran dan masukan untuk perbaikan skripsi. Penulis juga mengucapkan banyak terima kasih kepada Darbin Simatupang yang telah membantu penelitian selama di lapangan.

\section{DAFTAR PUSTAKA}

Betty J, Linda R, Lovadi I. 2015. Inventarisasi jenis paku-pakuan (Pteridophyta) terestrial di hutan dusun Tauk kecamatan Air Besar kabupaten Landak. Protobiont 4(1):94-102 .

Efendi WW, Hapsari FNP, Nuraini Z. 2013. Studi keanekaragaman tumbuhan paku di kawasan wisata Coban Rondo kabupaten Malang. Cogito Ergo Sum 2:173-188.

Fachrul MF. 2012. Metode Sampling Bioekologi.Jakarta: Bumi Aksara.

Indrianto. 2006. Ekologi Hutan. Jakarta: PT. Bumi Aksara. 
Katili. 2013. Deskripsi pola penyebaran dan faktor bioekologis tumbuhan paku (pteridophyta) di kawasan Cagar Alam Gunung Ambang kabupaten Bolaang Mongondow Timur. Jurnal Saintek 7(1): 35 41.

Khamalia I, Herawatiningsih R, Ardian H. 2018. Keanekaragaman jenis paku-pakuan di Kawasan IUPHHK-HTI PT. Bhatara Alam Lestari Kabupaten Mempawah. Jurnal Hutan Lestari 6(3): 510518.

Kusmana C, Hikmat A. 2015. Keanekaragaman hayati flora di Indonesia. Pengelolaan Sumberdaya Alam dan Lingkungan 5(2):187-198.

Magurran A. 1988. Ecological Diversity and Its Measurement. Bangor: Springer-Science + Business Media. B. V. pp: 7 - 45.

Odum EP. 1993. Dasar-Dasar Ekologi. Terjemahan Oleh Tjahjono salinan dari buku Fundamental
Of Ecology. Yogyakarta. Gadjah Mada University Press: 677-697.

Sandy SF, Pantiwati Y, Hudha AM, Latifa R. 2016. Keanekaragaman jenis tumbuhan paku (Pteridophyta) di kawasan Air Terjun Lawean Sendang kabupaten Tulung Agung. Prosiding Seminar Nasional II.

Sorianegara I, Indrawan A. 1988. Ekologi Hutan Indonesia. Bogor: Fakultas Kehutanan. IPB.

Tudjuki K, Ningsih B, Toknok. 2014. Keanekaragaman jenis tumbuhan obat pada kawasan hutan lindung di desa Tindoli kecamatan Pamona Tenggara kabupaten Poso. Jurnal Warta Rimba 2(1): $120-128$.

Widhiastuti RT, Alief A, Sari WDP. 2006. Struktur dan komposisi tumbuhan paku-pakuan di kawasan hutan Gunung Sinabung kabupaten Karo. Jurnal Biologi Sumatera 1(2): 38 - 41. 